University of Nebraska - Lincoln

DigitalCommons@University of Nebraska - Lincoln

$12-2-2020$

Examining and evaluating multilevel communication within a mixed-methods, community-based participatory research project in a rural, minority-majority U.S. Town

Angela L. Palmer-Wackerly

Maria S. Reyes

Sahra H. Ali

Kimberly Gocchi Carrasco

Patrick Habecker

See next page for additional authors

Follow this and additional works at: https://digitalcommons.unl.edu/commstudiespapers

Part of the Critical and Cultural Studies Commons, Gender, Race, Sexuality, and Ethnicity in Communication Commons, and the Other Communication Commons

This Article is brought to you for free and open access by the Communication Studies, Department of at DigitalCommons@University of Nebraska - Lincoln. It has been accepted for inclusion in Papers in Communication Studies by an authorized administrator of DigitalCommons@University of Nebraska - Lincoln. 
Authors

Angela L. Palmer-Wackerly, Maria S. Reyes, Sahra H. Ali, Kimberly Gocchi Carrasco, Patrick Habecker, Kristen Houska, Virginia Chaidez, Jordan Soliz, Julie A. Tippens, Kathryn Holland, Lisa M. PytlikZillig, Kali Patterson, and Kirk Dombrowski 


\title{
Examining and evaluating multilevel communication within a mixed-methods, community-based participatory research project in a rural, minority-majority U.S. Town
}

\author{
Angela L. Palmer-Wackerly, ${ }^{1}$ Maria S. Reyes, ${ }^{2}$ Sahra H. Ali, ${ }^{2}$ \\ Kim Gocchi Carrasco, ${ }^{3}$ Patrick Habecker, ${ }^{3}$ Kristen Houska, ${ }^{4}$ \\ Virginia Chaidez, ${ }^{5}$ Jordan Soliz, ${ }^{1}$ Julie A. Tippens, ${ }^{6}$ \\ Kathryn J. Holland, ${ }^{7}$ Lisa Pytlik Zillig, ${ }^{8}$ Kali Patterson, ${ }^{3}$ \\ and Kirk Dombrowski ${ }^{3}$ \\ 1 Department of Communication Studies, University of Nebraska-Lincoln, \\ Lincoln, NE \\ 2 Lexington Regional Health Center, Lexington, NE \\ 3 Minority Health Disparities Initiative, University of Nebraska-Lincoln, \\ Lincoln, NE \\ 4 Nebraska Institute of Agriculture and Natural Resources, University of \\ Nebraska-Lincoln, Lincoln, NE \\ 5 Department of Nutrition and Health Sciences, University of Nebraska- \\ Lincoln, Lincoln, NE \\ 6 Department of Child, Youth, and Family Studies, University of Nebraska- \\ Lincoln, Lincoln, NE \\ 7 Department of Psychology and Women's and Gender Studies Program, \\ University of Nebraska-Lincoln, Lincoln, NE \\ 8 Public Policy Center, University of Nebraska-Lincoln, Lincoln, NE
}

Correspondence - Angela L. Palmer-Wackerly apalmer-wackerly2@unl.edu

Published as: Angela L. Palmer-Wackerly, Maria S. Reyes, Sahra H. Ali, Kim Gocchi Carrasco, Patrick Habecker, Kristen Houska, Virginia Chaidez, Jordan Soliz, Julie A. Tippens, Kathryn J. Holland, Lisa Pytlik Zillig, Kali Patterson, \& Kirk Dombrowski (2020): Examining and evaluating multilevel communication within a mixed-methods, community-based participatory research project in a rural, minority-majority U.S. Town, Journal of Applied Communication Research, doi: 10.1080/oogo9882.2020.1851042

Copyright (C) 2020 National Communication Association; published by Routledge/Taylor \& Francis. Used by permission.

Submitted 13 September 2019; accepted 3 June 2020; published 2 December 2020. 


\title{
ORCID
}

Angela L. Palmer-Wackerly http://orcid.org/000o-0001-8384-5225

Patrick Habecker http://orcid.org/oooo-0003-4435-1593

Julie A. Tippens http://orcid.org/0000-0003-0465-3570

\begin{abstract}
Community-based participatory research (CBPR) has been shown to improve health and social well-being by including diverse, marginalized community voices within academic-community partnerships. Although CBPR has gained in popularity, an explicit examination and evaluation of communication processes and outcomes throughout an entire CBPR project is lacking. Here, we analyze interviews with 10 stakeholders (i.e. 4 academic and 6 community partners) about their experiences in a three-phase, mixed-methods project exploring Hispanic and Somali community members' perceptions of healthcare needs and access in a rural U.S. community. Results reflect that CBPR endeavors include communication challenges, successes, and ongoing tensions not simply between the academic group and community partners but also within these groups. We encourage academic- community research partners to devote considerable efforts to strengthening effective communication between and within multiple identity groups throughout an entire CBPR project (including evaluation) as they work to create, complete, and sustain project goals and outcomes.
\end{abstract}

Keywords: Community-based participatory research (CBPR), rural health, minority health, intergroup communication, mixed methods

Community-based participatory research (CBPR) involves non-academic researchers - community members, policymakers, and service providers - in the research process and the translation of research into policy and practice (Israel et al., 1998; Wallerstein \& Duran, 2006). Acknowledging the strengths of a university-community partnership (Israel et al., 1998; Wallerstein \& Duran, 2006), CBPR has examined various issues, including education, poverty, discrimination, housing, hunger, health, and religion (Harter et al., 2011). Many CBPR projects are founded upon social justice advocacy, seeking to work with marginalized populations to change civic and social outcomes (Warren et al., 2018). Regardless of focus, CBPR advances initiatives by assuming that interventions are strengthened by incorporating community insight, values, and norms (Wallerstein \& Duran, 2006).

CBPR brings at least two primary groups (academic and community) together to address social issues. Given their diverse perspectives, several communication challenges may occur between and within these groups. Reflecting between-group differences, academic 
and community partners - especially if community partners are marginalized (Minkler, 2004; Muhammad et al., 2015) - may have differences in goals (knowledge versus community improvements), approach (caution versus immediate change), rewards (publication versus positive community impact) (Israel et al., 1998; Spoth \& Greenberg, 2005; Teufel-Shone, 2011), and resources (power, time, and scientific knowledge versus lived experience) (Israel et al., 1998; Wallerstein \& Duran, 2006). However, within-group differences are equally important to recognize in CBPR collaborations. When striving for inclusive collaboration, within-group differences in perceptions and experiences may be communicated because of differences in critical resources (e.g. money, time, transportation) (Wendel et al., 2018), power and status (Wang \& Burris, 1997), perceptions of vulnerability (e.g. Scorgie et al., 2017), and differences in language and identity (e.g. Oaks et al., 2019). Accommodating diverse community voices within communication research becomes a prerequisite for project success that better serves communities (Dempsey et al., 2011).

Thus, the purpose of the current study is to examine and evaluate the multilevel communication practices between and within research groups across a 2-year CBPR project, HealthVoiceVision. The rural Nebraska-based project involved a team of academic partners across various disciplines working with community partners who identified as white, Hispanic, or Somali. Although partners agreed on a project goal (i.e. to centralize community voices in describing their health needs), partners experienced different research successes, challenges, and tensions based on their identities that affected project facilitation and evaluation. We interviewed all available partners to capture the intergroup communication complexities inherent in projects where multiple identities co-exist. Below, we give a detailed background on HealthVoiceVision, outline the method used in the current evaluation, and discuss implications for CBPR and intergroup communication.

\section{Background of HealthVoiceVision}

HealthVoiceVision was a 2-year CBPR project (2016-2018) conducted between the University of Nebraska-Lincoln (UNL), a large, Midwestern land-grant university, and partners in Lexington, $\mathrm{NE}$, a rural town 
of around 10,000 people, located $3 \mathrm{~h}$ away. Its goal was to capture the health experiences and needs of Lexington, which had seen dramatic demographic change - with Hispanic immigrants historically and Somali refugees recently - due to available work in a nearby meat processing plant. Since 2000, according to the 2010 census, Lexington increased its Hispanic population by 21\%, Black/African American population by $1441 \%$, Hawaiian Pacific Islander population by $1700 \%$, and population identifying with two or more races by $48 \%$ - while its White population decreased by $8 \%$, and non-Hispanic population decreased by $17 \%$ (Census Viewer, n.d.(a)). Currently, Hispanic individuals are the majority ethnic group, and combined with the other ethnic populations, Lexington is now considered an ethnic minoritymajority community.

These shifts are important for social, economic, and political reasons, and the project's goal was to provide qualitative and quantitative data related to health needs, assets, and experiences of residents as they intersected with social determinants of health. Although Lexington is the County seat, its health needs are largely undocumented because Nebraska reports health information at the county level, and Dawson County, with a population of 24,326 and a 78\% White alone population (Census Viewer, n.d.(b)), is distinct from Lexington's demographic population. The town's regional hospital and other community partners (e.g. community organizers) requested city-level data from university researchers so that they could use the data to apply for grants and increase healthcare access.

HealthVoiceVision engaged a CBPR model as both researchers and community members sought to co-create and share knowledge to benefit community goals (Minkler, 2004). The Rural Futures Institute, which partners with the Nebraska University system to address rural problems and create sustainable solutions, funded HealthVoiceVision. The project consisted of three phases: (1) a 10-week, photovoice project, wherein 13 participants described their health experiences through photos they took in focus groups during Spring 2017, (2) a survey of 325 participants, conducted through respondent-driven sampling over 10 days in October 2017, and (3) a photography exhibit Looking Past Skin, curated by academic and community partners and displayed at two museums to reach policymakers. 


\section{Current study of communication and CBPR}

The purpose of the current evaluation was to interview and share stakeholders' perspectives after HealthVoiceVision's completion, and IRB-approval (20180918570 EX) was conducted post hoc. Stakeholders were interviewed by the first author (i.e. co-investigator of HealthVoiceVision) and gave their perspectives based on their roles and involvement. Ten people were interviewed: 4 academic partners: the principal investigator [K.D.], two project managers [anonymous] and [K.G.C.], university extension staffer [K.J.H.]; and six community partners: three community health workers (CHWs) (1 Latina, 2 Somali) employed at Lexington Regional Medical Center-[M.S.R.], [M.A.H.], [S.H.A.], a county historical museum director [C.W.], a state history museum curator [S.K.], and a community organizer [G.G.]. Community voices were prioritized (Sandoval et al., 2012) through attempts to facilitate culture-centered listening, where participants share perspectives to invite different ways of thinking about community engagement (Dutta, 2014).

Data analysis consisted of reflexive thematic coding which included six coding phases (Braun et al., 2019; Saldaña, 2013). After familiarizing herself with the data, the first author generated codes through inductive reading of each interview transcript, memoing after each interview, and analyzing transcript readings to link codes to possible theoretical ideas. In the third phase, constructing themes, the first author identified patterns regarding (mis)communication between and within the research groups. After revising of themes to reflect chronological development of the project, a thematic map was constructed to define themes. In the final stage, producing the report, the findings were compared with insights from the current literature. In this final stage, the themes (i.e. communication between and within groups) were organized in chronological order and divided into successes, challenges, and tensions to examine and reflect the communication experienced by stakeholders.

The first author verified findings through member-checking (Birt et al., 2016), followed by separate discussions between the first author and four stakeholders (i.e. 2 academic, 2 community) to clarify language. What follows serves as an exemplar of the intergroup communication successes, challenges, and tensions involved in a 
community- based project comprising multiple, conflicting identities in a rural town with shifting ethnic-racial demographics.

Throughout this evaluation project, authors reflected on their positionality. Altogether 13 authors contributed to its design, data collection and analysis, and writing. All 11 academic authors were trained in social science and represented several disciplines: communication, anthropology, nutrition and health sciences, psychology, public policy, and sociology. The remaining authors were community health workers and worked for a regional rural health system. Of the academic authors, nine identified as white, one as multi-ethnic (white/Hispanic), and one as second-generation Mexican-American. The two community-based authors identified as Hispanic and Somali. Two academic authors were native to Nebraska, several were first-generation college graduates with CBPR training, with a few working from a feminist and social justice standpoint. All authors strived to reduce the hierarchies between researchers and community members while centralizing the experiences and needs of community members.

\section{HealthVoiceVision: communication successes, challenges, and ongoing tensions}

Our analysis of project communication illustrates how stakeholders are inevitably 'embedded in layers of context that can produce complementary and contradictory forces' (Brashers \& Babrow, 1996, p. 249), even as they work together. While findings supported extant literature that explains how CBPR is complex, time-intensive, and responsive to all involved (Minkler, 2004), novel findings revealed more nuanced communication dynamics (1) within a unique context (researchers partnering with two different community cultural groups in a rural minority-majority town) as well as (2) between and withingroup (mis)communication.

\section{Preparing for HealthVoiceVision: communication successes}

Before beginning a CBPR project, partners must assess university and community capacity and readiness (Wallerstein \& Duran, 2010). HealthVoiceVision involved diverse partners - both within and between 
the university and community groups; thus, much work had to be done to navigate these group identities to create and accomplish mutually beneficial goals and outcomes.

\section{Within-academic group communication successes}

Before conceptualizing HealthVoiceVision, the Minority Health Disparities Initiative (MHDI), a research initiative created by Nebraska's Tobacco Settlement Fund and tasked with improving minority health disparities statewide, had already prioritized frequent and effective community-based research. The University's investment was key to MHDI's success, but Nebraska was experiencing a budget crisis, which resulted in decreased University funds and competing intraorganizational goals. UNL administration had a directive/need to decrease funding; whereas MHDI had a desire/need to increase funding to support mission effectiveness. Thus, MHDI's director [K.D.] recognized that they had to communicate MHDI's value - their effectiveness in improving the quality of health and healthcare across Nebraska's communities. The director (1) invited the associate vice chancellor for research to serve on MHDI's community advisory board so that university leadership had direct contact with MHDI's successes and (2) used his start-up funds to create 'a super glossy annual report that tracked the progress we'd made and we gave it to everybody.' By bringing the university administration to the same space, MHDI successfully created momentum and credibility within the university, paving the way for the university to continue supporting MHDI's growth, despite the budget crisis.

Though MHDI worked with over 20 scholars, its community impact coordinator, a new and temporarily funded position, identified five new university researchers for HealthVoiceVision who had a community engagement research background and were looking to collaborate with like-minded researchers. MHDI affiliation helped researchers establish credibility and trust across Nebraska's communities, while the researchers provided MHDI with labor to create, facilitate, and analyze research. This collaboration mentored researchers by combining their complementary skills and knowledge to build the next generation of transdisciplinary health equity scholars. 
Between-academic and community group communication successes

While CBPR capacity was increasing at the university level, so too was community engagement between university researchers and community members. Community groups contacted Nutrition and Health Sciences faculty member [V.C.] to inform her of unmet health needs in rural Nebraska, including Lexington, and she put them in contact with MHDI, knowing of their outreach efforts into Nebraska's rural communities, particularly those with an influx of immigrants and refugees. Simultaneously, MHDI's director, a trained anthropologist and social networks expert, spoke with colleagues about rapidly changing local towns associated with meatpacking, including Lexington. He said:

I took a drive out there and I did my usual drive around...It was fascinating. I didn't really talk to anyone. I just wanted to get a sense of the place.

Lexington was chosen by academic and community partners as an ideal location to explore how the relationship between identity, place, and health were changing in the rural Midwest. Lexington also had a need for research, as the director said:

There was a tremendous white flight...yet everything was reported at the county level.... The situation in Lexington had gone one way, [while] the situation in the county had gone another. Classic white flight suburbanization stuff....The hospitals were telling us that, and the school was telling us that.

MHDI needed to understand the attitudes, perspectives, and experiences within the town, and MHDI's community impact coordinator, now turned project manager, visited Lexington. Making sure they heard from as many voices as possible, MHDI created a 10-question survey (i.e. 'scoping exercise') that the project manager asked community members to complete, asking afterwards, 'Well who else should I talk to?.' The survey constructed an informal network, an image of how the town was connected, and identified potential partners.

To connect community partners to one another, and to the university, MHDI organized projects addressing problems contributing to 
rural and ethnic health disparities. Projects included a high school curriculum for students to become community public health educators and a mental health intervention to train CHWs. These projects built upon each other, addressed multiple ecological levels within the community, and acquainted stakeholders, further creating capacity for HealthVoiceVision.

Involved with the mental health intervention above, the Lexington Regional Health Center was a major partner for HealthVoiceVision. Two Somali ([M.A.H.] [S.H.A.]) and one Hispanic [M.S.R.] CHW wanted to participate in the project for different reasons (i.e. curiosity and an open schedule, relating with the research, and wanting research experience to help their community, respectively). [C.W.], at the Dawson County Historical Society Museum, wanted to connect current events to the county's historical immigration experiences. Another project goal was to reach state policymakers, so the Nebraska History Museum in Nebraska's capital city, where the state legislature and university were located, was also chosen. [S.K.], the museum's curator of education, said the project merged with her passion to work with refugees and fit the museum's strategic goal and mission of expanding their audience, while showcasing Nebraska history. Both academic and community partners built relationships to increase capacity and intergroup trust while working to achieve a larger 'research team' identity with mutually beneficial goals.

\section{Designing and implementing the mixed-methods, three-phase project: communication successes}

The project design included a survey to gather city-level data for the hospital and community organizers who sought to build documented need for a free mobile clinic - both groups wanted to be able to quantify unmet health needs, including (in)access to healthcare services. However, to recruit survey participants, the research team knew they had to build trust among additional community members. Thus, MHDI's director suggested Photovoice, a qualitative research method that involves listening to participants' voices through the sharing of photos in focus groups and community forums (Wang \& Burris, 1997). To create spaces where community voices were the focus (Dutta, 2014), the academic team consulted with the hospital and, together, decided 
to create two separate Photovoice focus groups for Hispanic and Somali participants, led by CHWs over 8 weeks. Those findings would then inform a museum exhibit that would travel across Nebraska to share immigrant stories.

Phase 1: within-community communication successes via Photovoice

The theme 'Unite Dawson County' gave participants the chance to come together and learn from each other. Originally, Hispanic and Somali focus groups met separately, as researchers thought participants would be more comfortable with this design. As the project progressed, however, participants asked to meet together. The mutual feeling was that they already knew about their in-group experiences but wanted to learn about the other group's experiences. $\mathrm{CHW}$ [M.A.H.] explained 'I guess eventually we realized that we were asking the same questions, you know' and therefore 'we can get feedback from both Somali and Hispanic and we can compare and contrast at the same time.'

CHW [M.S.R.] also explained that Hispanic participants saw how Somali participants coped with similar frustrations (e.g. lack of accessible/affordable/safe housing) but also with different frustrations (e.g. not having as deep of a connection to, or belonging with, the larger town community). Other differences involved Somali participants having greater access to services through Medicaid than Hispanic participants because Somali participants often had refugee status and were more culturally open to using others' funds for medical costs (e.g. Medicaid, employer funds). CHWs recounted an example, which involved a photo of a Hispanic woman's finger with a tendon exposed. She had cut herself at her restaurant job with a knife, had tried at-home remedies to heal it (i.e. coffee grounds and onion peels), and $12 \mathrm{~h}$ later had her friend (and participant) drive her to the emergency room. The patient declined anesthesia during surgery. [M.S.R.] remembered that night:

I was an interpreter that night at ER, and I remember asking her all the time, 'Do you want more medicine?' [The patient responded,] 'I have put up with vaginal deliveries, this 
is nothing.' But you can see the gestures she was doing.... When you are undocumented and you working, you don't want to cause any problems and she knew that was a cost to the business... And the surgeon in the hospital, he did that surgery in that ER room. So she save a lot of money, too, to the owner of the business.

This story was new to Somali participants. CHW [M.A.H.] said:

Like I know for a fact that I've never seen that in our community... Somali people just avoid the whole surgery, in general... The last thing they want to do is even surgery, so there's a difference there.

She and [S.H.A.] explained that the Somali community is largely afraid of surgery from the uncertainty of not being able to 'fully recover.'

One challenge for CHWs was focus group participants who did not regularly show up; however, of those who showed, [M.S.R.] said, 'They feel confident, and they were sharing a lot of their stories.' In addition to sharing photos and why they were meaningful, participants completed a form to explain how the photo represented their viewpoints. These photos, forms, and transcribed meetings created the basis for the museum exhibits. [M.A.H.], who participated in the focus groups, saw a change across participants as meetings progressed:

They felt very comfortable. I feel like that, yeah, in the beginning, I felt like they were shy or maybe foreign to it...And eventually we eased into it. By the end, we had so many people, both Hispanic and Somali. That was really awesome.

There was laughter and storytelling in a mix of Spanish, Somali, and English; however, [M.S.R.] said, 'People were, like you know, they really were emotional at the same time.' Participants' disclosure of cultural and health stories created personal investment as they saw their reflections both resonating with and informing others. 
Phase 2: between and within-group communication successes

Originally, the research survey design used random spatial sampling, where researchers sample every fifth house in a clockwise direction on randomly selected neighborhood blocks. To help with easy identification of trusted researchers who had previously worked with community members, the team created t-shirts. However, as the PI explained, after the 2016 U.S. Presidential election, 'We didn't think anyone would talk to us.' He added:

We thought of the translation issues because the blocks would be linguistically mixed. Do you have four translators walking around with you and three are standing still all the time?... And we just thought, you know, people just aren't going to answer the door. This is not a friendly environment, for immigrants, in Nebraska.

Thus, respondent-driven sampling (RDS) was chosen as the new method to recruit participants. The CHWs knocked on doors, made reminder calls, and offered $\$ 25$ to community members if they took the survey and an additional $\$ 10$ for each referral. The survey was stationed at a fitness center (run by the hospital), a Spanish-speaking church, and the Somali Community Center. Within 10 days, 325 people had participated, and the survey closed. No identifying information was taken, and participants could confidentially participate through a self-administered survey in English, Somali, or Spanish using audio-computer-assisted self-interview (ACASI) software. Recruiting success was largely due to CHWs who were trusted members of their cultural communities. As CHW [M.A.H.] said:

The influence in this community is strong because we only had 20 people, and then those 20 people they felt confident and they told their friends, and their siblings. And then next thing you know, after 20 we had another 30. They were just coming in quick.

Thus, the survey preserved participants' anonymity while enhancing trust between the university and community and within the community. 
Phase 3: research translation successes: sharing cultural similarities and differences within museum exhibits

Although the project manager hoped to showcase photos in three to four exhibits across the state, two locations ultimately became more realistic. At the Dawson County Historical Society Museum, the exhibit, entitled Looking Past Skin, communicated stories by framing 48 photos on vintage-inspired window panes, accompanied by captions explaining the photographer's (i.e. participant) perspective. The exhibit connected participants' immigration stories to the historical pictures and words of Dawson County's former German and Scandinavian immigrants and included historical information like citizenship documents. Exhibit-goers also attended a simulation, 'Ask the Doctor,' to experience first-hand the difficulty of visiting a doctor who speaks another language. CHW [M.S.R.] explained the presentation's relevance and appeal:

I like the presentation like you pretend to meet a doctor. 'Cause I feel that it sometimes doesn't matter what part of the community you can be...people think they raise their voice, you know you will understand. The voice comes in English or Spanish, we don't understand each other.

Intercultural learning continued during exhibits, focusing on immigration and shared stories about family separation and fears of deportation. [C.W.], the director of the Dawson County Historical Society Museum, said:

I have to admit that I didn't really realize that any of this was really going on. We live in our culture and we are so, secluded, secularized...You know you have yourself in your own little world. So that was one nice thing about this project that you learn what's happening and going on around me that I had no clue.

CHW [M.S.R.], who speaks frequently with Hispanic community members about immigration issues, found this space to be enlightening: 
You know it was [an] eye-opener to talk about that [historical] migrant community...we find out birth certificates from people those years that they couldn't become a United States citizens... It's not new stuff; it's years before you're honored to be citizen of the United States.

This 'immigration throughout history' theme connected to the Nebraska History Museum exhibit months later. [S.K.] explained that she and her staff created a migration timeline complementing the exhibit: 'We are all immigrants, right? We all migrate, and you know, we've always been doing that. So, it was to begin 10,000+ years ago and bring us to the present so there seemed to be, you know, tie-ins.' Through research co-ownership, partners and community members learned about each other, from each other, in a way that connected them to each other, the region, and U.S. history.

Experiencing communication challenges within and between partnership groups. Conflicts throughout project implementation arose based on differences in roles and responsibilities, organizational pressures, and individual differences both within-academic partnerships and between-academic and community partners.

Within-academic group communication challenges. Because the research team involved three entities (MHDI, university administration, and the transdisciplinary research team), each balanced different roles, responsibilities, and intraorganizational pressures. The first conflict involved identity and communication between MHDI's director and project manager. As the PI explained, 'We were paying a good deal of money for her to hang out there, she had a car, hotel racking up fast against MHDI's budget, so part of our effort to get a grant was trying to get some of that cost off.' The university administration was supportive and found a grant, funded by the Rural Futures Institute, that helped temporarily. As MHDI's community impact coordinator, the project manager said she felt internal pressure to demonstrate organizational value. She was in tension between wanting to share ownership of the project to distribute the workload and wanting to demonstrate her long-term value to the university to gain more stable pay. As a result, her responsibilities split her time between visiting Lexington 
and applying for future grants, a workload that she said was unsustainable for one person to effectively handle. Academic researchers on the team helped to design the project, inform data collection, analyze data, and give troubleshooting advice. However, it was difficult to find time to meet as a team. As the project manager explained:

You end up running it alone because...research teams can't show up for ya. And so it's not that you're supposed to be doing most of the work, 'cause the theory is you're not, but you end up having to do so much of the work - the literature reviews [in grant applications]-... so that your researchers can engage for a short period of time.

Miscommunication stemmed from the dynamics of two parts of a university organization: MHDI, which worked primarily in research and in response to external grant pressures; and the research team, which worked in response to different departmental commitments spread across research, teaching, and service.

The project manager also experienced conflict with the university administration, which she said did not give support to manage smaller grants: 'We don't have the money to make budgetary mistakes...So that's one of the biggest challenges.' Thus, MHDI sought outside help to manage the project's finances.

Conflict escalated between the project manager and PI when an exhibit deadline was missed: For the PI, it was another deadline missed; for the project manager, it was an occurrence that should not outweigh 18 months of successful collaboration. The PI spoke of these tensions:

I did field work. I've been in the field for years at a time as an anthropologist so I get it. I get what pressure she's under. I get how hard it is. But, I also run an internal business so you have to be aware of opportunities that you are blowing and which ones you're getting.

Another conflict occurred when the project manager did not disclose that her romantic partner was the builder for the exhibit. For these reasons, the project manager quit and another MHDI staffer [K.G.C.] became the new project manager. On reflection, the first project manager 
felt that while hiring a former romantic partner killed the project's momentum and altered the research translation phase, it did not erase all of her success:

The purpose of this exploration of our project is to see what worked and own what didn't work. Accountability is core to learning from our humanness so that others can build on our mistakes. Without seeking the multiple truths of human experiences, how we are going grow from here?'

Tensions between information sharing and project clarity led to a lack of trust within the academic team. As the PI observed, 'There are academic research tensions with the team and with the administration. It wasn't just the community. There were fewer academic research tensions with the community than there were with the university.'

Between-academic and community group communication challenges. Project timing gave rise to the first university-community challenge: grant deadlines do not often align with the lives of community members (de Souza, 2013). Focus groups were originally scheduled to meet over 8 weeks, during January and February 2017, at the hospital; however, they were delayed by 2 months until enough participants were recruited.

Another communication challenge occurred during project exhibits. From the community partners' perspective, the planning lacked transparency, and information was not shared equally. The museum director [C.W.] said that they did not see much of the planning and 'had to trust that it was happening.' The museum curator in the state history museum [S.K.] said that she met the exhibit builder once: 'It was hard for us to know what was going on and yet it was quickly approaching. There were definitely some conceptual ideas but there were just plenty of uncertainties.' Additionally, the exhibit originated in one community $3 \mathrm{~h}$ away; and coordinating two museums with the exhibit builder while managing two projects created at different times, was difficult. The museum curator explained, 'It just became too much. There were lots of tentacles.' [S.K.] said things improved when [K.G.C.], the second project manager, the PI, and the PI's son finished the second exhibit over the winter holiday: 'I felt like once they 
stepped in, it was like, "Okay we're going to get this thing done" and they did.' However, from the second project manager's [K.G.C.'s] perspective, she had to create a new project without historical knowledge of it, partnership details, or help from the first project manager, which resulted in some tense conversations trying to navigate 'who's gonna do what, and where things are gonna be located, how big things are going to be, 'cause things hadn't even been constructed at this point.'

The CHWs also talked about disorganization and miscommunication leading up to the exhibit. As [M.H.] said, 'It was a little frustrating towards the end' when they arrived at the county museum 2 days before the exhibit opened, and nothing was constructed. Opening night was to include an intercultural celebration of Hispanic and Somali food and dance, but when the CHWs brought their dresses to the museum as instructed, they had to store them because the exhibit was not ready. During opening night, photos were not hung on the wall; instead, they were on the ground, propped up against the wall. As [M.H.] said, 'I don't know why the pictures weren't ready. It was, there was some difficulty communications [sic].'

This complicated the community's trust in the university. However, retrospectively, [C.W.], the county museum director said she wanted to partner with the university and community again but would explicitly communicate more to:

know a little more on what to expect ... to make sure I have an exhibit on time... and maybe a better schedule .... [the first project manager and the builder] were coming in and working on it all night long and that made me nervous having them in the museum all night. And, the city police are always, they check, and they called me a couple times ... and I told them that I know someone's in there ... and they thought that was kind of odd that they were doing it overnight.

To the second project manager [K.G.C.], [C.W.'s] feedback is a reminder that clear communication should continue throughout CBPR and that keeping promises is paramount:

I think it all comes back to the communication. Honestly, everybody needs to set those boundaries and those expectations 
to begin with, just to set up the rest of the project so that it can at least go as smoothly as possible.

\section{Completion of project: ongoing communication tensions in evaluating and sustaining project outcomes}

Although much effort was devoted to creating shared identities and goals within the research team, different identities can result in different evaluations of whether projects met their desired goals.

Within-academic group communication

University partners largely viewed this project as a success. Not only did MHDI have an internal team that was working cohesively toward the goal of improving minority health disparities statewide, but it had a faculty research team solidified, too. The PI said: 'We are trying to figure out how you create cultures, or collectives of people who work with and trust each other, who could potentially scale up and do other projects.' It was also the first time MHDI had managed a project with a 'modular' organizational style (i.e. clusters of individuals focused around a specific job function) versus a 'pyramidal' style (i.e. one researcher running the project and overseeing personnel). The study had two modules wherein researchers were not supervising the team but were collaboratively informing the project and analyzing the results, expanding it beyond one PI's expertise. The PI explained:

And, that's a really good outcome. The researchers who are affiliated and associated with the project are free to actually do stuff that I would never think of .... and so [the modular style is] something that creates that creative space. Collaborative creative space is something that we should support.

Between-academic and community group communication

From the academic team's perspective, the study set the groundwork for future collaborations with community members. As project manager [K.G.C.] said: 
The cool part is now that all of this infrastructure has been built, we have people there that are willing to work with us, we have a community that knows us. So the next project is not gonna be the same, it's gonna be a lot easier, and not to say that it's not gonna be difficult, 'cause it will, but different kind of difficult.

Capacity change also occurred between the university, the community, and the surrounding state population, not only within museums but also workplaces and schools. The first project manager explained:

We got the first cross-cultural communication happening. These were community leaders that showed up to do this and they had never spoken to each other. They had never asked the questions of each other like they asked in the photovoice project. They never thought to think about the differences about when the Latino, Spanish-speaking group of people come in and attempt to build a life for themselves and then the Somalis and the differences that prejudice has and how racism works. And how that starts working upwards.

[K.H.] from UNL Extension said she saw the same openness in schools across the state regarding conversations on cultural differences and the effects of racism:

One of the big takeaways I got was students are ready for it. They are ready to look into those, I don't know what you want to call it, messy topics or wicked problems, and see how it effects them and their families and communities and they're willing to make change around those problems and have their voices heard. They just need to be heard.

A common conflict within CBPR occurs around the process of research, especially the time it takes to disseminate results (Minkler, 2004). HealthVoiceVision partners continually negotiated these conflicts through communication and learned to accommodate each other. For example, Dawson County Historical Society Museum director [C.W.] 
suggested that to work with the university, community members should know:

There's so many procedures and rules and regulations ... the university has to cover its butt somehow and I think with small communities, there's the gentleman's agreement. We wouldn't think we'd have to sign a form just to talk to people but a lot of people out here don't understand or realize that.

Project manager [K.G.C.] agreed that explaining 'bureaucratic stuff' to community members is hard:

This stuff takes so much time [and] community members don't understand how long it takes to do research. They don't and they expect it to be instantaneous and the change to be instantaneous, and change is very slow and it can seem like it's, there's nothing happening.

Within-community group communication differences

From a community perspective, at least one mutual goal was accomplished: the museum exhibits showcased community voices about immigration. At the first exhibit's opening night, an intercultural gala celebrated participants' backgrounds. Most importantly, perhaps, the CHWs [M.A.H.] and [S.H.A.], the community organizer [G.G.], and the informally recognized male leader of the Somali community [who was abroad during the time of this evaluation] - all spoke about how meaningful the cross-cultural communication was, as well as the resulting increased trust and relatedness. The second project manager [K.G.C.] said: 'That event was probably one of the most moving things that I had experienced on the community level. I mean I've been to a lot of community events but to see that much momentum was pretty inspiring.'

However, [G.G.] questioned the inclusion of supplementary photos in the exhibit taken by a professional photographer, who was not part of either cultural group: 'There was a professional White photographer hired to take additional pictures...Isn't this supposed to be through our lens? Right? And, it didn't become that anymore.' According to the academic team, the photographer was hired when it became 
apparent that many of the participants' photos were low resolution, and the museums needed photos to better promote the exhibits. While [G.G.] expressed that she did not like this, the project team balanced community goals (i.e. participant photographs) with museum goals (having large, clear images) and promotional goals (flyers/brochures), and kept community photos as the exhibit focus, leaving the professional photos for marketing. Whereas the academic team and some of the community members saw this compromise as still showcasing community voices, other community members, such as [G.G.], saw this compromise as an outside group member (white, professional photographer) taking away the power and centrality of community voices.

The second exhibit at the Nebraska History Museum in the state's capital included a legislative reception with state politicians on opening night. This exhibit communicated immigrant experiences to a larger Nebraska community, and museum curator [S.K.] said listening and learning from these diverse voices and especially during the legislative reception was critical to project success:

That was probably, you know, definitely the climactic moment.... And I really got quite positive responses. I think they felt good about it. I think people felt good seeing themselves represented in a museum..... It's great to say, 'This is your mission, you really want a more diverse audience', but to be actually able to build off one-offs, and you know keep that thing going, is really great.

However, in CBPR, 'there is always more to do.' After project completion, questions remained, but for many community partners, there were not many answers. A goal in CBPR is that the community own the research. With the exhibit stored at the county historical museum, [C.W.] thought [G.G.] wanted to use it. However, [G.G.] did not know its location. [C.W.] also had questions. For the community, she wanted to know about 'the follow-up stuff. I think we wanted to see, "So here's the questions asked, here's the problem, so what are we going to do about it?" There was none of that, I feel.' With researchers, she thought, 'But now what? I think that was the point, like, "Let's get this started, and you guys take it from here." It took us a while to figure that out.' 
Co-led by [G.G], one post-project community initiative was the creation of a free mini-clinic. One year after the project ended, the research team returned to present the survey results to the community, and the presentation ended with community organizers detailing the mini-clinic plan. They hoped the survey results would document the need for the mini-clinic. However, as [G.G.] explained:

There's a high probability that [the participants] have insurance already. And individuals who didn't have insurance might have not been interviewed. We're doing more surveys so we're doing them in a way that we think we should do them. And hopefully we can establish data that allows us to move forward either by presenting it to the hospital or by establishing our own mini clinic.... If it wasn't for the [clinic] committee that chose to move forward for action then it would have just been a project.

The research team and community members wanted additional research supporting systemic change for health outcomes (i.e. improve mental health, cancer, and trust in U.S. hospitals and medical treatment), and they also wanted to improve social determinants of health (i.e. affordable, quality housing; better community preparation during immigration raids). CHW [M.S.R.] said, 'Well you know, we don't have any Spanish-speaking counselors, and that is an issue. We don't have any Somali either.' [M.S.R.] desired to educate immigrants more about 'their rights, not to be afraid, speak up, because the outcome can be in their benefit instead of against them.'

Stakeholders expressed wanting to do more research together. Nebraska History Museum curator [S.K.] explained wanting the university to know: 'We're here and we're hungry for it and you know we appreciate having that partnership.' Not all research was welcome though. For example, [G.G.] mentioned a study focusing on violent extremist groups: 'Is there an option to say, "No thank you" as a community?' She understood participants have the right to opt out of research, 'but I want more than just one individual to say no; I want all of us to say no because it's not productive for our community.' However, she was enthusiastic about working with a university graduate student whose thesis focused on the community's health care inaccess. 
[G.G.] explained, 'It was just a coincidence and/or like a blessing that he's willing to help us get some more answers specifically with our lower socioeconomic individuals in our community and access to medical care.'

Based on their roles and identities, academic partners largely viewed HealthVoiceVision as meeting their project goals, while community partners differed in their evaluation of the project's success and sustainability.

\section{Discussion: improving CBPR communication, practice, and sustainability}

While the negotiation of academic and community identities, cultural structures, and expectations has been central to CBPR literature (e.g. Teufel-Shone, 2011; Wallerstein \& Duran, 2010), the current project illustrates the importance of also recognizing diversity within the academic and community partner groups, not just between groups. Previous research has indicated that professional identities and corresponding perspective-taking can influence professional goals (Hewett et al., 2009), especially within diverse teams (Aritz \& Walker, 2010; Ayoko et al., 2002). This process is amplified when working with diverse partners on multiple ecological levels, where the communication dynamics become even more complex. Below, we discuss implications for future CBPR studies.

\section{Theoretical implications}

While existing literature illustrates CBPR complexities (Harter et al., 2011), it misses the nuances of navigating identities within academia. Gallois et al. (2018) explain that miscommunication is often blamed on an individual's personality differences rather than 'misaligned goals or structure' (p. 313), and that individuals within organizations 'interpret these institutions and their situations in their own ways' based on individual identities (p. 313). When an employee failed to disclose that the exhibit builder was a romantic partner, the PI (considering his 'in-group' organizational roles, values, and pressures) saw a serious ethical violation. The project manager (considering her perceived 
'outsider status' as a community organizer and its roles, values, and pressures) saw a one-time mistake involving misplaced trust in her romantic partner. Thus, time should be designated for creating trust within the academic team as well.

The study's goal for Phase 1 (Photovoice) was to capture differences between cultural groups via separate focus groups; however, Hispanic and Somali community members were more interested in disclosing across groups to enhance intercultural understanding, illustrating a desire to move from 'us versus them' to 'we' (Gaertner et al., 2000). This cooperation resulted in the sharing of 'intercultural moments' wherein communication partners worked through cultural similarities and differences as communication unfolds (Bolden, 2014). Thus, participants wanted to process and disclose information together starting from Phase 1.

In any CBPR project, 'community voice' should be interrogated, ensuring that multiple voices (not only the powerful) are represented and listened to (Dempsey et al., 2011; Dutta, 2014; Wang \& Burris, 1997). In our study, CHWs recruited within their networks and participants were diverse between and within these groups: former refugees and immigrants from different countries and cultures, (un)documented immigrants, people who did (not) speak English, and people who lived in Lexington, Nebraska, and the U.S. for different lengths of time. Community partners perceived our research in different ways, as shown in the disagreement about project value, and diverse voices need to be included to manage tensions around representativeness. Future CBPR studies could examine how promoting inter-organizational tensions rather than preventing them allows for deeper collaboration and engagement (Woo, 2019). Ultimately, identity co-construction and reflexivity between CBPR partners and groups is important; however, we must equally consider communicative identity co-construction within partnership groups (Collier \& Lawless, 2016).

\section{Practical implications}

Faculty members struggle to foster greater engagement between universities and communities when faculty have rigid tenure requirements that incentivize quick publishing instead of community relationship development (Warren et al., 2018). Likewise, academic 
partners are nested within larger institutional groups - departments, colleges, and centers - that operate within different administrative and funding structures. These structures affect the expectations, norms, pressures, values, and priorities with which each group member interacts. As universities encourage interdisciplinary and transdisciplinary research (Parrott \& Kreuter, 2011), convergence between faculty and departments, departments and colleges, and colleges and universities is increasingly important in accommodating group differences. Departments, colleges, and universities should recognize community engagement as time-intensive research and provide adequate time for community travel and relationship building. However, researchers should also promote their research in a way that meets university goals for positive relationships with community members, increased community engagement, and increased external funding to offset budget pressures. As our findings illustrate, the PI's effective upward communication of the MHDI's research successes met the administration's needs (Welsh et al., 2019), which in turn helped the project's progress. Self-promotion of research is not always a priority for researchers, but this project exemplifies its importance, particularly in accommodating supervisors, and thus creating CBPR capacity (Sandoval et al., 2012).

Our study illustrates the challenges of building academic-community partnerships in a location $3 \mathrm{~h}$ away. Land-grant universities have Extension offices, whose purpose is to connect research to local communities; our study shows the underutilized potential of partnering with Extension in CBPR. This study also shows the importance of faculty and staff traveling to, learning from, and creating relationships with community members on multiple levels to increase trust and capacity building for future CBPR; however, without MHDI's community impact coordinator position, it is unlikely that the project would have been possible. A further tension is the temporary nature of grant funding, which creates a 'drop in and leave' structure, where researchers arrive in communities with funding to examine a problem and then leave once the resources are gone (Minkler, 2004). Though sustainability is a key CBPR element, and a current requirement for some external funding applications, it is difficult to achieve in practice because (1) partners define 'sustainability' and 'effectiveness' differently and (2) generating grant funding takes considerable time. Thus, 
sustainability plans should be explicitly discussed, outlined at the outset, and revisited, including contingencies for continued community involvement if future funding efforts are unsuccessful.

\section{Limitations}

Although our project evaluation interviews included diverse perspectives from stakeholders, it was not possible to talk to some project participants, namely a Somali community leader who was abroad at the time of the study, other photovoice participants, and other community members who attended the exhibits. It is possible that these participants would have expressed views not represented here. Future CBPR studies should incorporate feedback from multiple project stakeholders at the end of each project stage to gain an even more nuanced understanding of CBPR impact and to minimize the challenges of community members providing feedback after the project ends. It is also possible that stakeholders did not express all of their opinions, given that they were part of the same research team with most hoping to collaborate in the future (Buller \& Burgoon, 1996). However, even within these constraints, stakeholders gave valuable, constructive feedback, which can be used to enhance within- and betweengroup understanding for future CBPR projects.

\section{Conclusion}

The current study addresses gaps in CBPR and communication literature: (1) to examine and evaluate multilevel communication within CBPR in a rural, ethnic minority- majority town; and (2) to understand how intra- and intergroup communication practices affect CBPR processes and outcomes. Communication was pivotal in creating capacity for CBPR in current and future projects, guiding the research design, and explaining challenges and tensions between and within partnerships. To help inform future projects, we show how members often stretched between multiple identities to work toward a group vision and identity. Navigating tensions is difficult, and integrating perspective-taking into all stages of CBPR projects could enhance empathy, trust, and collaboration between and within partnership groups. 
Acknowledgments We wish to thank Lexington Regional Health Center staff, including Mulki Hussein; the Dawson County Historical Society Museum and Director Crystal Werger; Nebraska History Museum and Curator of Education Sharon Kennedy; Two Rivers Health Department Director Jeremy Eschliman; and the Nebraska DHHS Office of Minority Health Administrator Josie Rodriguez. Without their help and support, this project would not have been possible. We also thank Grecia Macias, Alyssa Kobza, Nestor Hernandez, Beza Bekele, and Kamryn Sannicks for their help with transcribing interviews. And, finally, we wish to thank the people of Lexington, NE, who generously shared their stories and time with us through Photovoice focus groups, exhibits and completing the survey.

Disclosure No potential conflict of interest was reported by the authors.

Funding This work was supported by the Rural Futures Institute at the University of Nebraska; University of Nebraska-Lincoln's College of Arts and Sciences: [Grant Number Enhance Grant/21-0524- 0011]; Nebraska Agricultural Experiment Station with funding from the Hatch capacity funding program from the USDA National Institute of Food and Agriculture: [Grant Number Accession Number 1011764].

\section{References}

Aritz, J., \& Walker, R. C. (2010). Cognitive organization and identity maintenance in multicultural teams: A discourse analysis of decision-making meetings.

The Journal of Business Communication, 47(1), 20-41. https://doi. org/10.1177/0021943609340669

Ayoko, O. B., Härtel, C. E. J., \& Callan, V. J. (2002). Resolving the puzzle of productive and destructive conflict in culturally heterogeneous workgroups: A communication accommodation theory approach. International Journal of Conflict Management, 13(2), 165-195. https://doi.org/10.1108/ebo22873

Birt, L., Scott, S., Cavers, D., Campbell, C., \& Walter, F. (2016). Member checking: A tool to enhance trustworthiness or merely a nod to validation? Qualitative Health Research, 26(13), 1802-1811. https://doi. org/10.1177/1049732316654870

Bolden, G. B. (2014). Negotiating understanding in "intercultural moments" in immigrant family interactions. Communication Monographs, 81(12), 208-238. https://doi.org/10.1080/03637751.2014.902983

Brashers, D. E., \& Babrow, A. S. (1996). Theorizing communication and health. Communication Studies, 47(3), 243-251. https://doi. org/10.1080/10510979609368479

Braun, V., Clarke, V., Hayfield, N., \& Terry, G. (2019). Thematic analysis. In P. Liamputtong (Ed.), Handbook of research methods in health social Sciences (pp. 843-860). Springer. https://doi.org/10.1007/978-981-10-5251-4 103 
Buller, D. B., \& Burgoon, J. K. (1996). Interpersonal deception theory. Communication Theory, 6 (3), 203-242. https://doi. org/10.1111/j.1468-2885.1996.tboo127.x

Census Viewer. (n.d.(a)). Population of Dawson County: Nebraska. https://www. census.gov/quickfacts/dawsoncountynebraska

Census Viewer. (n.d.(b)). Lexington, Nebraska Population. https://www.census. gov/quickfacts/lexingtoncitynebraska

Collier, M. J., \& Lawless, B. (2016). Critically reflexive dialogue and praxis: Academic/practitioner reflections throughout a formative evaluation of Circles $®$ USA. Journal of Applied Communication Research, 44(12), 156-173. https://doi.org/10.1080/oogog882.2016.1155724

Dempsey, S., Dutta, M., Frey, L. R., Goodall, H. L., Madison, D. S., Mercieca, J., Nakayama, T., \& Miller, K. (2011). What is the role of the communication discipline in social justice, community engagement, and public scholarship? A visit to the CM Café. Communication Monographs, 78 (2), 256-271. https://doi.org/10.1080/03637751.2011.565062

de Souza, R. (2013). The business of doing interventions: A paradox for the participatory method. In M. J. Dutta, \& G. L. Kreps (eds.), Reducing health Disparities: Communication interventions (pp. 395-418). Peter Lang Publishing.

Dutta, M. J. (2014). A culture-centered approach to listening: Voices of social change. International Journal of Listening, 28(2), 67-81. https://doi.org/10.108 o/10904018.2014.876266

Gaertner, S. L., Dovidio, J. F., Nier, J. A., Banker, B. S., Ward, C. M., Houlette, M., \& Loux, S. (2000). The common in-group identity model for reducing intergroup bias: Progress and challenges. In D. Capozza, \& R. Brown (Eds.), Social identity processes (pp. 133-148). Sage Publications.

Gallois, C., Watson, B. M., \& Giles, H. (2018). Intergroup communication: Identities and effective interactions. Journal of Communication, 68(2), 309-317. https://doi.org/10.1093/joc/jqx016

Harter, L. M., Hamel-Lambert, J., \& Millesen, J. L. (2011). Participatory partnerships for social action and research. Kendall Hunt.

Hewett, D. G., Watson, B. M., Gallois, C., Ward, M., \& Leggett, B. A. (2009). Intergroup communication between hospital doctors: Implications for quality of patient care. Social Science \& Medicine, 69(12), 1732-1740. https://doi. org/10.1016/j.socscimed.2009.09.048

Israel, B. A., Schulz, A. J., Parker, E. A., \& Becker, A. B. (1998). Review of community-based research: Assessing partnership approaches to improve public health. Annual Review of Public Health, 19(1), 173-202. https://doi. org/10.1146/annurev.publhealth.19.1.173

Minkler, M. (2004). Ethical challenges for the "outside" researcher in communitybased participatory research. Health Education \& Behavior, 31(6), 684-697. https://doi.org/10.1177/1090198104269566

Muhammad, M., Wallerstein, N., Sussman, A. L., Avila, M., Belone, L., \& Duran, B. (2015). Reflections on researcher identity and power: The 
impact of positionality on community based participatory research (CBPR) processes and outcomes. Critical Sociology, 41(7-8), 1045-1063. https://doi. org/10.1177/0896920513516025

Oaks, L., Israel, T., Conover, K. J., Cogger, A., \& Avellar, T. R. (2019). Communitybased participatory research with invisible, geographically-dispersed communities: Partnering with lesbian, gay, bisexual, transgender and queer communities on the California central coast. Journal for Social Action in Counseling \& Psychology, 11(1), 14-32. https://doi.org/10.33043/ ISACP.11.1.14-32

Parrott, R., \& Kreuter, M. W. (2011). Multidisciplinary, interdisciplinary, and transdisciplinary approaches to health communication: Where do we draw the lines? In T. Thompson, R. Parrott, \& J. Nussbaum (eds.), Handbook of health communication (2nd ed., pp. 3-17). Routledge.

Saldaña, J. (2013). The coding manual for qualitative researchers (2nd ed.). Sage Publications.

Sandoval, J. A., Lucero, J., Oetzel, J., Avila, M., Belone, L., Mau, M., Pearson, C., Tafoya, G., Duran, B., Iglesias-Rios, L., \& Wallerstein, N. (2012). Process and outcome constructs for evaluating community-based participatory research projects: A matrix of existing measures. Health Education Research, 27(4), 680-69o. https://doi.org/10.1093/her/cyro87

Scorgie, F., Vearey, J., Oliff, M., Stadler, J., Venables, E., Chersich, M. F., \& DelanyMoretlwe, S. (2017). "Leaving no one behind": Reflections on the design of community-based HIV prevention for migrants in Johannesburg's inner-city hostels and informal settlements. BMC Public Health, 17(1), 1-12. https://doi. org/10.1186/s12889-017-4351-3

Spoth, R. L., \& Greenberg, M. T. (2005). Toward a comprehensive strategy for effective practitioner- scientist partnerships and larger-scale community health and well-being. American Journal of Community Psychology, 35(3-4), 107-126. https://doi.org/10.1007/s10464-005-3388-0

Teufel-Shone, N. I. (2011). Community-based participatory research and the academic system of rewards. AMA Journal of Ethics, 13(2), 118-123. https://doi. org/10.1001/virtualmentor.2011.13.2.pfor1-1102

Wallerstein, N., \& Duran, B. (2010). Community-based participatory research contributions to intervention research: The intersection of science and practice to improve health equity. American Journal of Public Health, 100(S1), S40-S46. https://doi.org/10.2105/AJPH.2009.184036

Wallerstein, N. B., \& Duran, B. (2006). Using community-based participatory research to address health disparities. Health Promotion Practice, 7(3), 312323. https://doi.org/10.1177/1524839906289376

Wang, C., \& Burris, M. A. (1997). Photovoice: Concept, methodology, and use for participatory needs assessment. Health Education \& Behavior, 24(3), 369-387. https://doi.org/10.1177/109019819702400309

Warren, M. R., Calderón, J., Kupscznk, L. A., Squires, G., \& Su, C. (2018). Is collaborative, community- engaged scholarship more rigorous than traditional 
scholarship? On advocacy, bias, and social science research. Urban Education, 53(4), 445-472. https://doi.org/10.1177/0042085918763511

Welsh, E. T., Henderson, K. E., \& Diehn, E. W. (2019). "Aren't bosses supposed to manage you?" A qualitative study of managing your boss. Journal of Managerial Issues, 31(1), 65-84.

Wendel, M. L., Garney, W. R., Castle, B. F., \& Ingram, C. M. (2018). Critical reflexivity of communities on their experience to improve population health. American Journal of Public Health, 108(7), 896-901. https://doi.org/10.2105/ AJPH.2018.304404

Woo, D. (2019). Reconceptualizing interorganizational collaborations as tensile structures: Implications of conveners' proactive tension management. Communication Monographs, 86 (2), 158-183. https://doi.org/10.1080/036377 51.2018 .1526389 